\title{
PENERAPAN AUGMENTED REALITY PADA PEMBELAJARAN MENGENAL TANAMAN DAN BUNGA DENGAN METODE MARKER BASSED TRACKING
}

\section{IMAM KHOIRUDIN}

Teknik Informatika, Fakultas Teknik Universitas Maarif Hasyim Latif, Sidoarjo, Indonesia e-mail : imamkhoirudin02@gmail.com

\section{ABSTRAK}

Indonesia memiliki potensi yang sangat besar dalam penyedian tumbuhan dan bunga karena sumber daya tersebut tersimpan di dalam hutan dan belum termanfaatkan dengan baik. Dengan adanya aplikasi ini diharapkan membantu proses pengenalan dan pembelajaran macam-macam tanaman dan bunga serta manfatanya terkhusus bagi orang-orang yang belum mengenal dan belum mengerti macam-macam tanaman dan bunga yang sedang mepelajari atau meneliti.

Kata kunci : augmented reality, ar, pembelajaran, mengenal tanaman, bunga

\section{PENDAHULUAN}

Konsep Augmented Reality adalah menggabungkan dunia nyata dan virtual, bersifat interaktif secara Real-time, dan merupakan animasi 3D. Pada Augmented Reality terdapat 2 metode yang digunakan yaitu: marker based tracking dan markerless.

\section{METODE PENELITIAN}

Sistem perancangan diagram alur, use case diagram, squence diagram, activity diagram, perancangan dan desain aplikasi dimulai dengan rancangan detail dari yang sudah disertakan di aplikasi.

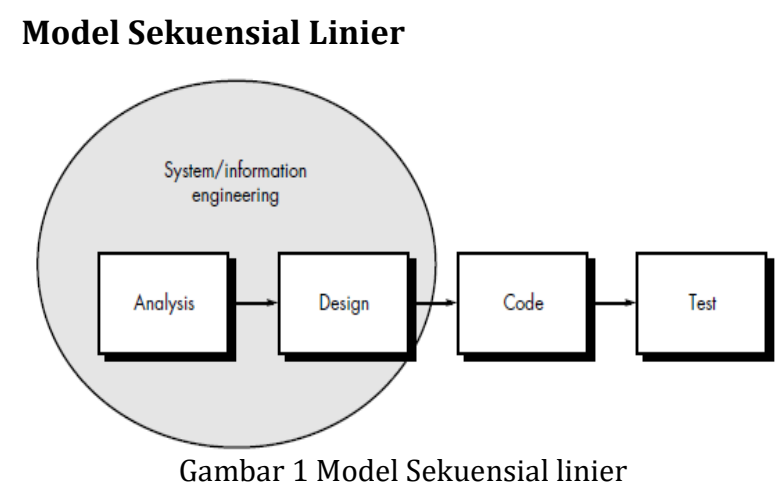

Proses perancangan Aplikasi Pengenalan Jenis tanaman dan bunga Berbasis Marker Augmented Reality Pada Platform Android menggunakan metode Sequensial Linier. Model sekuensial linier mengusulkan sebuah pendekatan kepada perkembangan perangkat lunak sistematik.

\section{Diagram Alur}

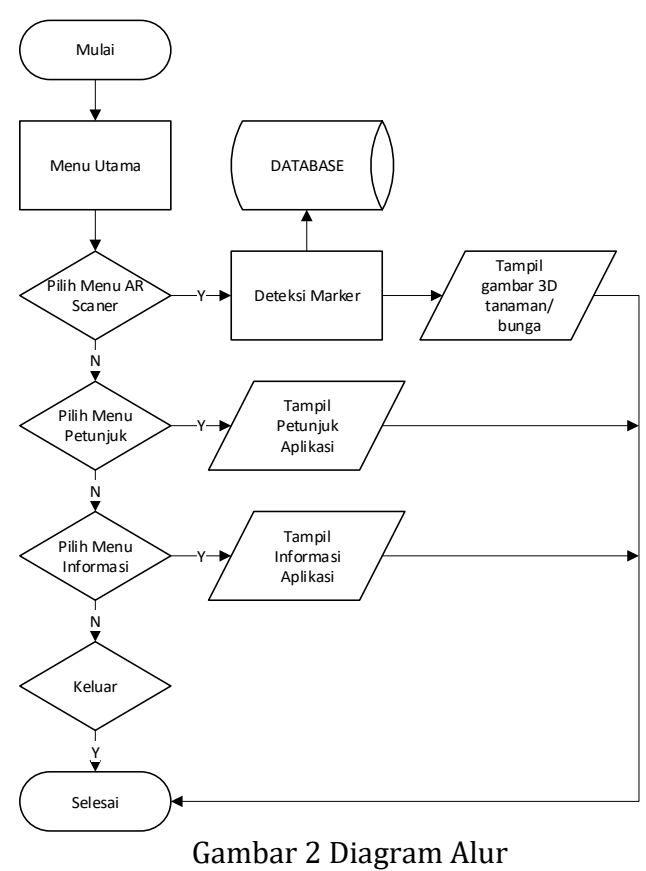

Berdasarkan diagram antarmuka pengguna, terdapat beberapa menu yang terdapat pada aplikasi yakni menu Utama, informasi dan petunjuk 1. Halaman utama, pada halaman ini menampilkan halaman menu utama dari aplikasi, pada halaman utama ini terdapat beberapa menu yang bisa dipilih oleh pengguna untuk menjalankan aplikasi ini diantaranya, Menu AR Scanner, Menu Petunjuk, dan Menu Informasi.

2. Menu AR Scaner, pada menu ini merupakan pilihan untuk menampilkan Augmented Reality berupa informasi mengenai tanaman dan bunga, yaitu teks, dan 3D dari tumbuhan dan bunga yang terdeteksi lalu akan dibandingkan dengan data marker yang ada dalam database, saat kemiripan mendekati $100 \%$ gambar output akan dikeluarkan. 
3. Menu Petunjuk, pada menu ini menampilan petunjuk penggunaan aplikasi.

4. Menu Informasi, pada menu ini merupakan menu untuk menampilkan informasi dari aplikasi mulai dari pembuat, asal aplikasi dan informasi lainnya terkait plikasi Pengenalan tentang tanaman dan bunga.

5. Menu Keluar, pada menu ini merupakan menu untuk keluar dari aplikasi. Database didalam berisi data gambar 3D dan output tampilan aplikasi, selain itu di Database juga berisi gambar marker untuk pencocokan dengan gambar yang nantinya akan di scan

\section{Use Case Diagram}

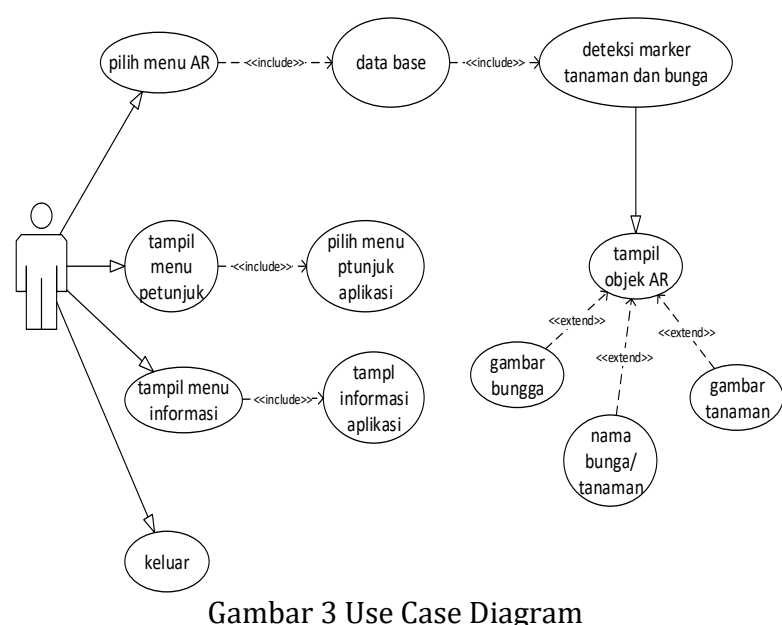

Gambar Use case diagram dari aplikasi pengenalan Tanaman dan bunga berbasis Augmented Reality, aktor dalam hal ini bertindak sebagai pengguna melakukan interaksi terhadap sistem. Interaksi yang dilakukan. Database berisi data gambar 3D dan output tampilan aplikasi, selain itu di Database juga berisi gambar marker untuk pencocokan dengan gambar yang nantinya akan di scan

1. Pilih menu AR dimana pada use case ini terhubung ke use case deteksi marker tanaman dan bunga, lalu tampil Objek AR.

2. Tampil menu petunjuk

3. Tampil menu informasi

4. Keluar

\section{Diagram Alur System Augmented Reality}

Terdapat beberapa menu yang terdapat pada aplikasi yakni menu Utama, informasi, petunjuk dari mendeteksi marker sampai tampilnya gambar 3D

1. menu petunjuk pada menu utama pada halaman ini adalah mendeteksi gambar marker augmented reality gambar tanaman dan bunga.

2. pada menu selanjutnya ini adalah pencocokan gambar augmented reality dengan yang ada di data base
3. menu petujuk pada menu ini merupakan untuk memvalidasi marker. jika gambar marker salah akan kembali ke awal pendeteksi keluar gambar marker berhasil maka akan tampil

4. menu informasi, pada menu ini merupakan menu untuk menampilkan hasil gambar 3d yang sudah terdeteksi

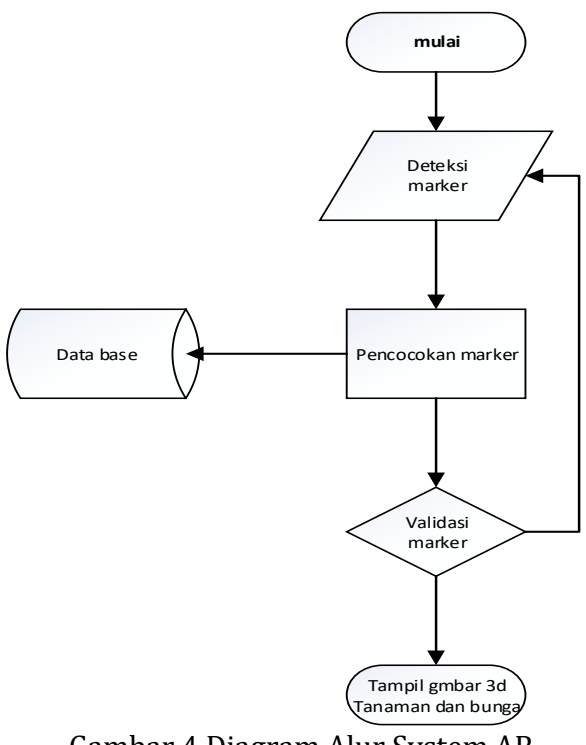

Gambar 4 Diagram Alur System AR

\section{Sequence Diagram}

Pada Sequence diagram menggambarkan urutan dari penggunaan aplikasi yang dimulai dari user yang menjalankan aplikasi. Sehingga aplikasi akan mengaktifkan kamera, kemudian mendeteksi marker. Apabila terdeteksi maka akan dilakukan pencocoka pola marker, ketika pola cocok maka aplikasi akan menampilkan objek $A R$ kepada User tersebut. Apabila pola dan markerless tidak terdeteksi, maka akan kembali ke pengaktifan kamera. Adapun tampilan sequence diagram terdapat pada gambar 5 .

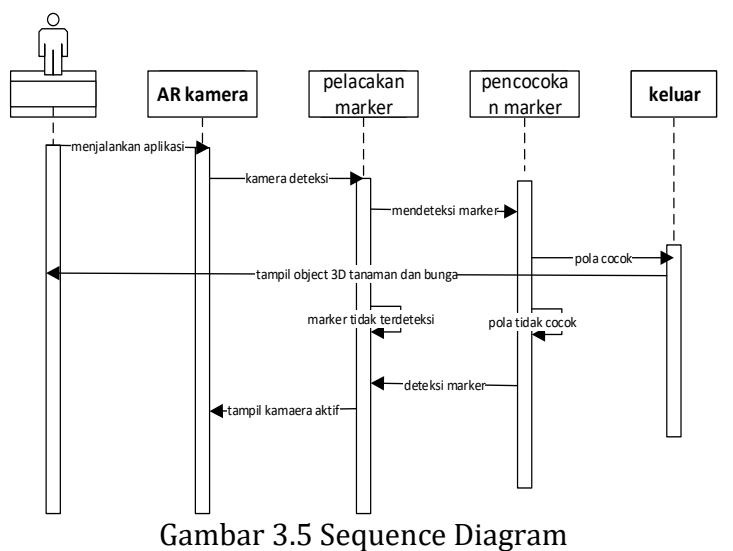

\section{Activity Diagram}

Pada gambar 6 merupakan tampilan Activity diagram aplikasi penganalan macam tanaman dan bunga berbasis Augmented reality pengambaran diagram di atas menujukan bagaimana aktifitas 
yang terjadi ketika penguna menjalankan aplikasi tesebut.

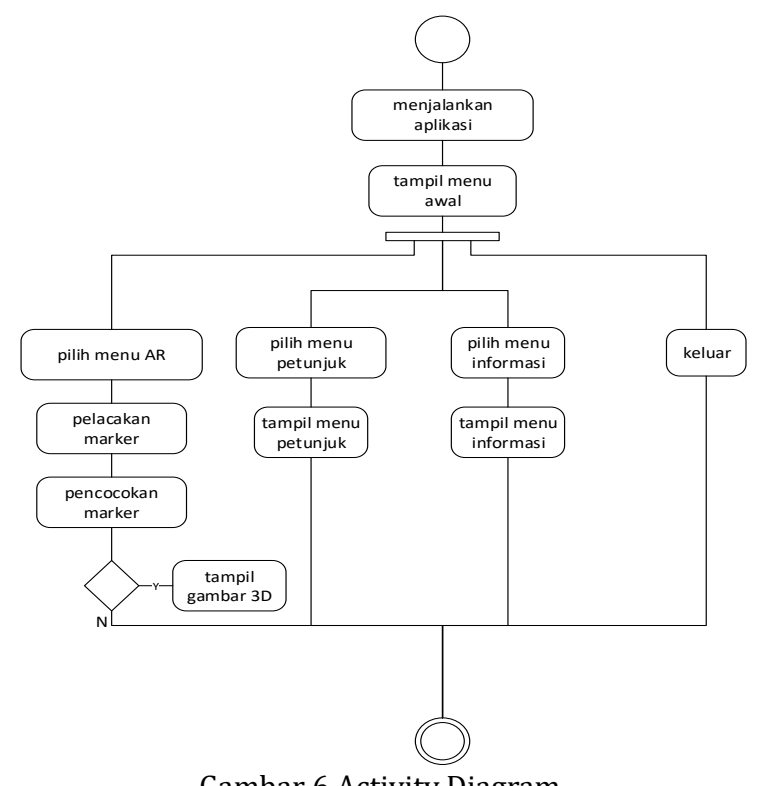

Gambar 6 Activity Diagram.

\section{HASIL PENELITIAN}

Pada penelitian ini akan dijelaskan bahwa yang dikerjakan oleh Pemantauan Kesehatan Pasien Dengan Metode Simple Additive Weighting (Saw) Berbasis Mobile Application Android adalah: 1. Aplikasi Mobile Android Pemantauan Kesehatan Pasien

2. Aplikasi memeliki fitur 2 level login yaitu level login admin dan level login pasien

3. Aplikasi berfungsi untuk menetukan rawat inap atau rawat jalan mengunakan metode SAW.

4. Aplikasi admin memiliki 5 menu yaitu beranda, input hasil diagnose, data pasien, data kamar dan logout.

5. aplikasi penganalan macam tanaman dan bunga berbasis Augmented reality 3 menu yaitu menu utama, petunjuk dan informasi.

\section{Menu Utama}

$$
\text { My AR }
$$

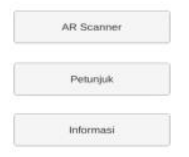

Gambar 7 Menu Utama
Pada tampilan menu utama akan tampil beberapa menu sebagai berikut yaitu menu utama yang menampilkan scanner $\mathrm{AR}$, menu petunjuk aplikasi, menu informasi aplikasi.

\section{Menu Petunjuk Aplikasi}

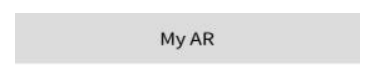

Gambar 8 Menu Petunjuk Aplikasi

Menu petunjuk aplikasi ini berfungsi sebagai petunjuk aplikasi yang berisi langkah - langkah menjalankan aplikasi tersebut

\section{Menu Informasi}

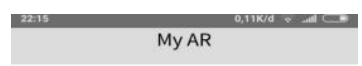

Gambar 9 Menu Informasi

Tampilan informasi ini berfungsi menampilkan informasi tentang aplikasi yang akan dijalankan yang berisi siapa si pembuat aplikasi, kapan dibuat dan nama jurusan.

\section{Tampilan Scanner AR}




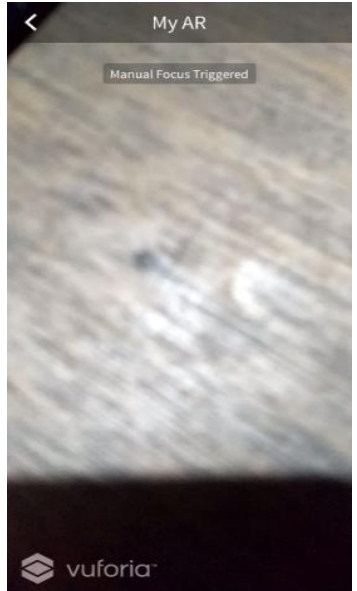

Gambar 10 Tampilan Scanner AR

Menu Scanner ini berfungsi sebagai alat merekam gambar dari marker yang akan direkam oleh kamera untuk menghasilkan gambar 3D.

\section{Bunga Tulip}

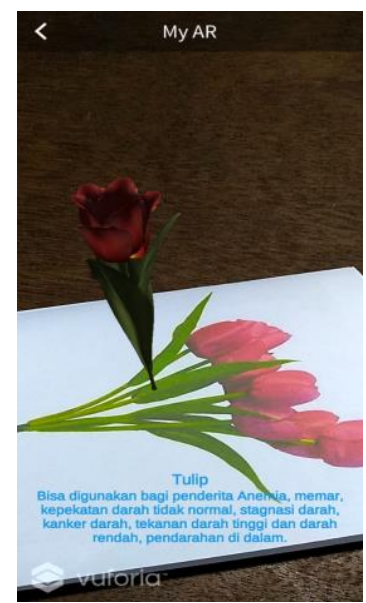

Gambar 11 Bunga Tulip

Bunga tulip bisa digunakan penderita anemia, memar, kepekatan darah tidak normal, sragnasi darah, kanker darah, tekanan darah tinggi, darah rendah dan pendarahan di dalam.

\section{Bunga Krisantumum}

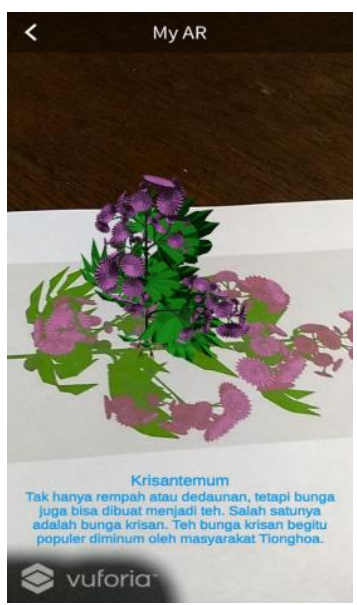

\section{Gambar 12 Bunga Krisantemum}

Tidak hanya rempah atau dedaunan, tetapi tanaman ini juga bisa dibuat menjadi teh. Salah satu nya adalah bunga krisan. Teh bunga krisan popular diminum oleh masyarakat tionghoa.

\section{Bunga Snowdrop}

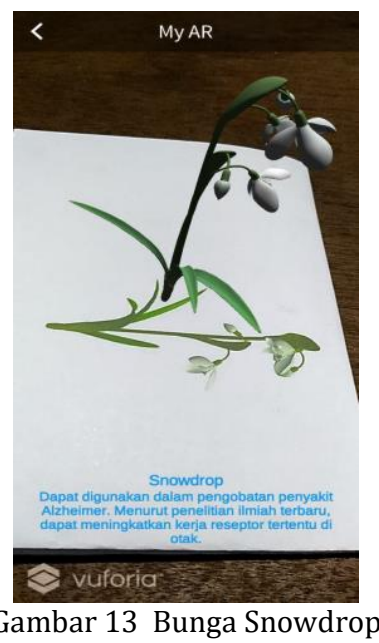

Bunga ini dapat digunakan dalam pengobatan penyakit Alzheimer. Menurut penelitian ilmiah terbaru, dapat meningkatkan kerja reseptor tertentu di otak.

\section{Anomone}

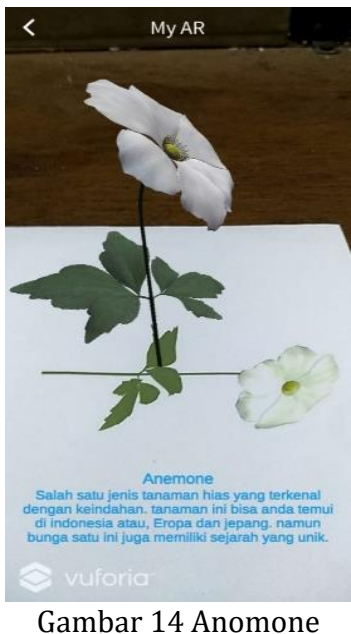

Salah satu tanaman hias yang terkenal dengan keindahan. Tanaman ini bisa ditemui di Indonesia atau Eropa dan Jepang. Namun bunga satu ini juga memiliki sejarah yang unik.

\section{Bunga Mawar}




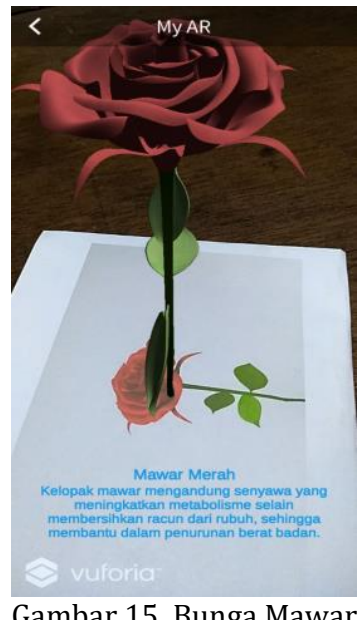

Kelopak bunga mawar mengandung senyawa yang meningkatkan metabolisme.

\section{PENUTUP}

Aplikasi mobile ini dapat menscan gambargambar tumbuhan dan bunga. Untuk menscan gambar menggunakan metode marker bassed tracking. Kesalahan data yang diterima oleh sistem bergantung pada gambar yang discan.

Setelah dilakukan pengujian dengan melakukan survey maka dapat dihitung jumlah nilai pada setiap indikator dengan nilai rata -rata 89.

\section{DAFTAR PUSTAKA}

[1] S. Aminah, E. Wardenaar, and Muflihati, "Tumbuhan Obat Yang Dimanfaatkan Oleh Battra di Desa Sejahtera Kecamatan Sukadana Kabupaten Kayong Utara," J. Hutan Lestari, vol. 4, no. 3, 2016.

[2] C. Patrik, R. Sabloak, J. Petrus, and Yoannita, Visualisasi 3 Dimensi Desain Interior Perabotan Rumah Berbasis Augmented Reality Pada Mobile Phone Dengan Sistem Operasi Android. STMIK GI MDP - Teknik Informatika, 2013.
[3] W. Gunawan, "PENGEMBANGAN APLIKASI BERBASIS ANDROID UNTUK PENGENALAN HURUF HIJAIYAH," J. Inform., vol. 6, no. 1, pp. 69-76, Apr. 2019.

[4] Uliontang, E. Setyati, and F. H. Chandra, "PEMANFAATAN AUGMENTED REALITY PADA MEDIA PEMBELAJARAN SEJARAH TENTANG BENDA-BENDA BERSEJARAH PENINGGALAN KERAJAAN MAJAPAHIT DI TROWULAN MOJOKERTO," Tek. Eng. Sains J., vol. 4, no. 1, pp. 19-26, Jun. 2020.

[5] A. Syahrin, M. E. Apriyani, and S. Prasetyaningsih, "ANALISIS DAN IMPLEMENTASI METODE MARKER BASED TRACKING PADA AUGMENTED REALITY PEMBELAJARAN BUAH-BUAHAN," J. Ilm. Komput. dan Inform., vol. 5, no. 1, 2016.

[6] T. T. Zuono et al., "Build design introduction to university profiles using the logo with the augmented reality method," in Journal of Physics: Conference Series, 2019, vol. 1175, no. 1, p. 12115 .

[7] Z. Mubarok, "PERANCANGAN DAN PEMBUATAN APLIKASI PEMBELAJARAN BANGUN RUANG 3D BERBASIS ANDROID DENGAN MEMANFAATKAN AUGMENTED REALITY," Ubiquitous Comput. its Appl. J., vol. 2, no. 1, pp. 29-38, 2019.

[8] D. S. Laksono, "PENERAPAN TEKNOLOGI AUGMENTED REALITY PADA ANDROID SEBAGAI MEDIA PEMBELAJARAN HURUF AKSARA JAWA BAGI ANAK DIDIK SETINGKAT SLTP," Ubiquitous Comput. its Appl. J., vol. 1, no. 1, pp. 67-80, 2018.

[9] A. B. Riza, "PENERAPAN TEKNOLOGI AUGMENTED REALITY PADA ANDROID SEBAGAI MEDIA PEMBELAJARAN PENGENALAN HARDWARE KOMPUTER BAGI ANAK DIDIK TINGKAT SLTP," Ubiquitous Comput. its Appl. J., vol. 1, no. 1, pp. 61-66, 2018. 
I Khoirudin / Ubiquitous: Computers and its Applications Journal, Vol. 3, No. 2, Desember 2020, 93-98 